\title{
34.3 GHZ ACCELERATING STRUCTURE FOR HIGH GRADIENT TESTS*
}

\author{
O.A. Nezhevenko, V.P. Yakovlev, J.L. Hirshfield, G.V. Serdobintsev", \\ S.V. Schelkunoff, Omega-P Inc., New Haven, CT 06511, USA. \\ B.Z. Persov, Budker INP, Novosibirsk, 630090, Russia
}

\begin{abstract}
To determine the maximum accelerating gradient and thus the length of a future multi-TeV electron-positron linear collider, one has to know the breakdown limit in any accelerating structure. A special accelerating structure has been designed for testing up to accelerating gradients of $300-350 \mathrm{MeV} / \mathrm{m}$ using the $45 \mathrm{MW}, 34.3 \mathrm{GHz}$ pulsed magnicon amplifier [1]. The $2 \pi / 3,57 \mathrm{~mm}$-length accelerating structure contains 19 cells and operates in standing wave (SW) mode in order to achieve maximum surface electric field.
\end{abstract}

\section{INTRODUCTION}

The customary accelerating structure for linear colliders is a $2 \pi / 3$ structure with a normalized group velocity $v_{g} / c$ in the range $0.02-0.1$. As is discussed in ref. [2], the maximum accelerating gradient $E_{\text {acc }}$ is determined mainly by the maximum tolerable electric field on the cavity surface $E_{m}$. Thus, the maximum accelerating gradient for fixed surface field is achieved if the overvoltage factor $k_{m}=E_{m} / E_{\text {acc }}$ is minimized. To minimize $k_{m}$, a disk edge geometry was suggested [3] having an elliptical crosssection. In the structure described below, the cell size and shape were chosen in order to minimize $k_{m}$ for a group velocity $v_{g} / c$ of about 0.05 [4]. This may be a reasonable choice in light of recent experiments with various X-band accelerating structures at SLAC $[5,6]$. These SLAC tests show upstream iris damage and phase advance changes as high power is applied. One explanation is that the higher group velocity at the upstream end of the structure leads to more energy being absorbed in a breakdown arc. It may also explain why early prototype structures at low group velocities performed well at high gradients (for example, a $75 \mathrm{~cm}$ long NLC structure with $v_{g l} / c=0.05$ was processed to $90 \mathrm{MeV} / \mathrm{m}$ without any apparent phase change. A series of low group velocity $\left(v_{g} / c \approx 0.05\right) \mathrm{X}$ band structures are being built at SLAC to verify the model and as a first step to develop a high gradient version for NLC/JLC [5]. Under these circumstances the choice of $v_{g} / c=0.05$ appears altogether logical since it will allow comparison of maximum achievable gradients at Ka-band and X-band under similar conditions.

\section{THE TEST STRUCTURE}

The test structure layout and field map for $2 \pi / 3 \mathrm{SW}$ mode is shown in Fig. 1, and parameters of this structure are listed in Table 1.

*Work supported by DoE

"Permanent address: Budker INP, Novosibirsk, 630090, Russia

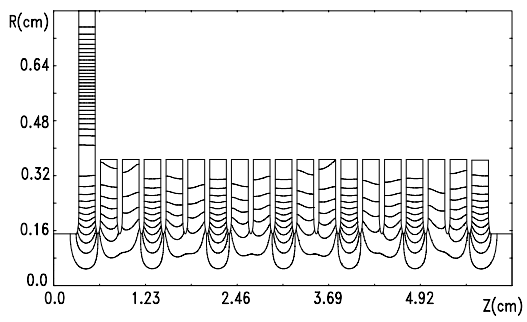

Figure 1. The 19-cell test structure layout with the $\mathrm{TM}_{020}$-input cell and field map for $2 \pi / 3 \mathrm{SW}$ mode.

Table 1. Parameters for the proposed Ka-band accelerating structure.

\begin{tabular}{|l|l|}
\hline Operating frequency, $f$ & $34.272 \mathrm{GHz}$ \\
\hline Operating mode & $2 \pi / 3, \mathrm{SW}$ \\
\hline Number of cells, $N$ & 19 \\
\hline Group velocity & $0.048 c$ \\
\hline Diameter of regular cells & $7.322 \mathrm{~mm}$ \\
\hline Diameter of aperture & $3.0 \mathrm{~mm}$ \\
\hline Wall thickness, $t$ & $0.70 \mathrm{~mm}$ \\
\hline Eccentricity, (see A in Fig.4) & 0.7 \\
\hline Overvoltage factor $k_{m}=E_{m} / E_{a c c}$ & 2.0 \\
\hline Overvoltage factor $(\mathrm{SW})$ & 3.84 \\
\hline Shunt impedance $(\mathrm{SW})$ & $65 \mathrm{MOhm} / \mathrm{m}$ \\
\hline Quality factor & 3800 \\
\hline Pulse width (adjustable) & $0.1-1 \mu \mathrm{sec}$ \\
\hline
\end{tabular}

It is anticipated that the actual $Q$-factor of the structure will be about $10 \%$ lower than the calculated value due to surface imperfections. One also should take into account a $15 \%$ reduction of the input power due to Ohmic losses in the waveguides. Because of this, the number of cells in the structure was reduced to 19 from 21 as discussed in [4], in order to achieve a surface gradient beyond 530 $\mathrm{MV} / \mathrm{m}$ using $30 \mathrm{MW}$ of $34.3 \mathrm{GHz}$ power, as an expected limit according to the CERN experiments at $30 \mathrm{GHz}$ [7]. It emerged that it would be difficult to couple power into the structure using four input waveguides on account of the small cell diameter for the $\mathrm{TM}_{010}$ mode. Accordingly, it was decided to use a first cell operating in the $\mathrm{TM}_{020}$ mode as the input coupler, thereby leading to an additional reduction of the field enhancement factor caused by coupling slots. The field pattern in the $\mathrm{TM}_{020}$ mode input cavity is shown in Fig. 2. The coupling slot sizes were determined based on 2D simulations using the CLANS code [8]. Because the $\mathrm{TM}_{020}$ mode is used, there is no field enhancement caused by the coupling. 


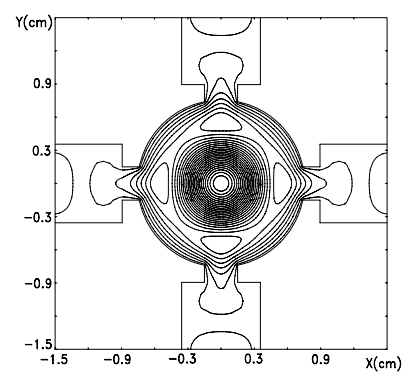

Figure 2. Field map in the transverse cross section of the input cell with $\mathrm{TM}_{020}$ mode

In Fig. 3 is shown the radial dependence of the electric field in the first cell for two values of azimuthal angle, namely $90^{\circ}$ (where the slots are located), and $45^{\circ}$ (between the slots).

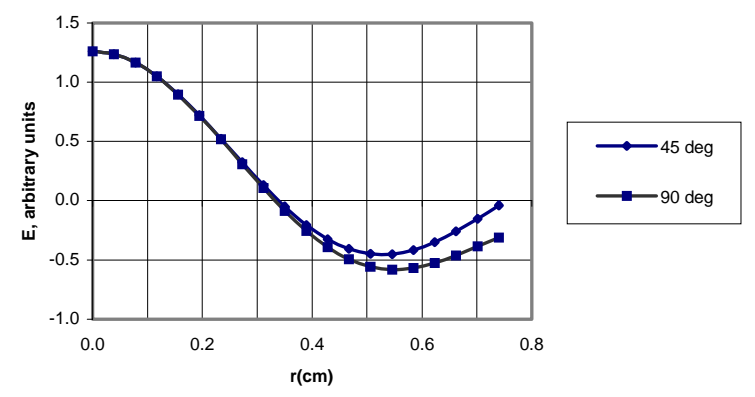

Figure 3. Electric field dependence on radius for two values of azimuthal coordinate.

The preliminary engineering design of the structure is given in Fig. 4. The structure consists of 18 regular cells in the $\mathrm{TM}_{010}$ mode (l) and the $\mathrm{TM}_{020}$ mode input cell (2), which is excited by four WR-28 waveguides (3). Mechanically the structure consists of 17 similar sections (4), plus input and output flanges. Each section (4) has a resonance cell (see A in Fig. 4), two circular flats for diffusion bonding, and a groove of $20 \mu$ depth for brazing, which is necessary to provide mechanical strength. Alloy, which fills the groove during brazing, is placed initially into special reservoirs (5). Each section has four holes which in the assembled structure constitute the cooling channels. The input flange consists of the body (6), four cooling pipes (7), four WR-28 waveguide flanges (8), and a mini-conflat $1-1 / 3^{\prime \prime}$ flange (9) for connection with the electron injector, pumping, etc. The four down-tapered waveguides (10) are built into the body of this flange. The output flange (11) also has a mini-conflat 1-1/3" flange. Since this design embodies pumping from both ends of the structure, anticipated vacuum in the structure is below $10^{-9}$ Torr (after baking). The four cooling channels (7) allow removal of the $300 \mathrm{~W}$ average power (30 MW, $1 \mu \mathrm{sec}, 10 \mathrm{~Hz}$ ), for maintaining azimuthal temperature uniformity of $1{ }^{\circ} \mathrm{C}$, and for providing necessary fine-tuning in the range of $12 \mathrm{MHz}$ by water temperature variation, for example from 30 to $50^{\circ} \mathrm{C}$.
For a $34.3 \mathrm{GHz}$ structure, cavity sizes are small and it is difficult to tune the frequency of individual cells. Thus, the method to be employed here is that commonly used at $\mathrm{X}$-band $(14 \mathrm{GHz})$ and $\mathrm{K}$-band $(30 \mathrm{GHz})$ : namely, the cells are manufactured with maximum achievable precision, the resonance frequency of each cell is measured, and the cells are selected and assembled in optimal order to minimize the field non-uniformity and to get the resonance frequencies as close as possible to the design frequency. The magnicon bandwidth is about 20 $\mathrm{MHz}$; thus the individual cavity resonance frequencies should not differ from the design frequency by more than $\pm 5 \mathrm{MHz}$. The final structure tuning will be provided by temperature adjustment of the coolant circulating through the structure.
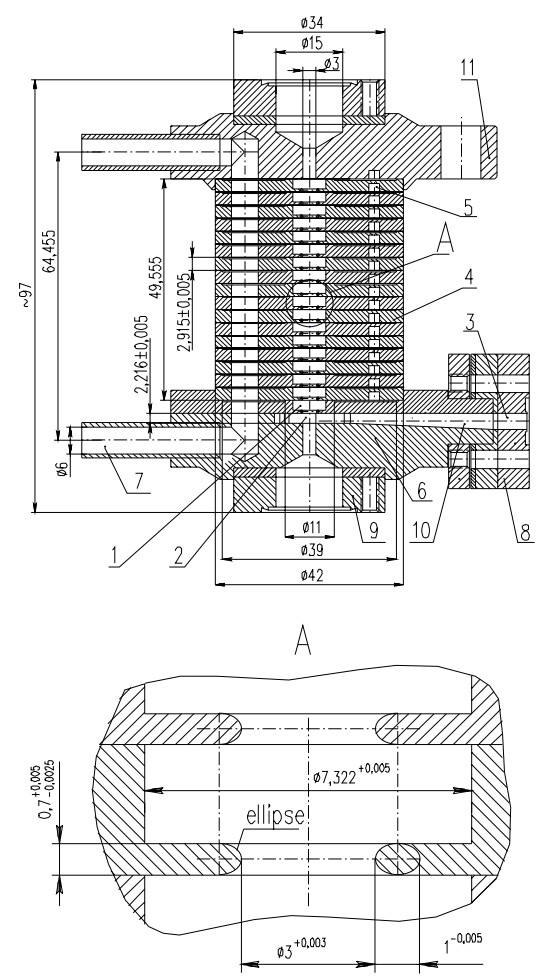

Figure 4. Preliminary engineering design of the structure. 1 - regular $\mathrm{TM}_{010}$ cells, 2- input $\mathrm{TM}_{020}$ cell, 3 - WR-28 waveguides, 4- regular sections, 5 - alloy reservoirs, 6 body of the input flange, 7 - cooling pipes, 8 - WR-28 waveguide flanges, 9 - conflat $1-1 / 3^{\prime \prime}$ flange, $10-$ downtapered waveguides, 11 - output flange, A resonance cell.

Cold-test measurements of the structure model were performed at an operating frequency of $34 \mathrm{GHz}$. Sixteen regular cells plus two half-cells with small holes for the probes were manufactured at the Yale Gibbs Shop. The measurements showed that, even in a shop which has little experience in fabricating millimeter-wave accelerating structures, the manufacturing accuracy can be sufficient to provide an acceptance rate of about $65 \%$. Moreover, fabrication of elliptical apertures has also been shown to be accurate enough to provide the desired group velocity. 
The scheme for accelerating structure feeding is shown in Fig. 5 (top view). One can see that each of four magnicon outputs is connected without a window to an input of the accelerating structure by WR-28 vacuum waveguide. Each WR-28 waveguide is able to transmit rf power at a level of more than $20 \mathrm{MW}$, and attenuation $(0.6 \mathrm{~dB}$ in our case $)$ is still acceptable. Because the 34.3 $\mathrm{GHz}$ magnicon is a third-harmonic amplifier, the phase shift between neighboring wavegude outputs spaced by $90^{\circ}$ in azimuth, is $270^{\circ}$. However the signals exciting the accelerating structure should have the same phase. Thus, for phase tune there are phase shifters in each waveguide arm having a range of phase shift of $180^{\circ}$.

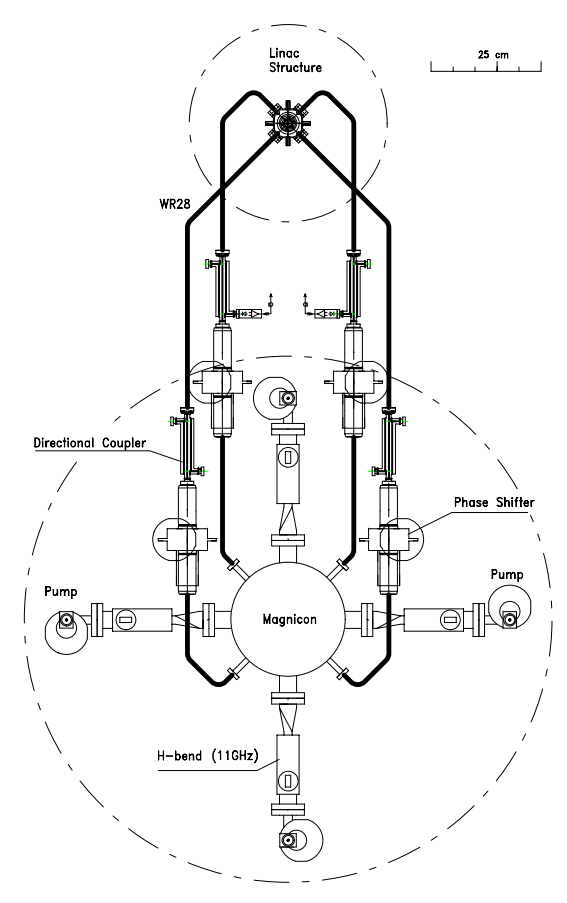

Figure 5. Scheme of accelerating structure feeding.

\section{DISCUSSION}

The anticipated rf power output from the Omega-P 34.3 $\mathrm{GHz}$ magnicon is about $40 \mathrm{MW}$. Taking into account a realistic shunt impedance and unavoidable rf power losses in connecting waveguides surface fields and accelerating gradients up to $690 \mathrm{MV} / \mathrm{m}$ and $180 \mathrm{MeV} / \mathrm{m}$ are anticipated in the accelerating structure described. This surface gradient corresponds to an accelerating gradient greater than $340 \mathrm{MeV} / \mathrm{m}$ for operation in the travelingwave mode. It can be noted that, in order to achieve 530 $\mathrm{MV} / \mathrm{m}$ of surface electric field (similar to [7]) in the structure described here, less than $20 \mathrm{MW}$ of drive power is required.

However, it should be noted that achievement of an accelerating gradient of $200-250 \mathrm{MeV} / \mathrm{m}$ in the test structure should not imply that the structure in an operating linac will be robust enough to stand metal fatigue and subsequent cavity surface destruction caused by pulse heating during 10-20 years of collider operation.
As shown in $[9,10]$ one should not expect the tolerable pulsed temperature rise for copper to be greater than 120 $140^{\circ} \mathrm{C}$. For the structure described here with $\mathrm{Z}_{\mathrm{H}}=\mathrm{E}_{\mathrm{acc}} / \mathrm{H}_{\text {max }}$ $=330 \mathrm{Ohms}$, the temperature rise during the pulse will vary between 85 and $270^{\circ} \mathrm{C}$ for an accelerating gradient of $200 \mathrm{MeV} / \mathrm{m}$ and a pulse width between $0.1 \mu \mathrm{sec}$ and 1 $\mu$ sec. One might conclude that for pulses of $100-150 \mathrm{nsec}$ there should be no problem with pulse heating, but this is not so. For example, design of the CLIC structure [11] shows a temperature rise of $250^{\circ} \mathrm{C}$ for an accelerating gradient of $150 \mathrm{MeV} / \mathrm{m}$ and a pulse width of $130 \mathrm{nsec}$. The reason for this substantial difference is that in the multi-bunch mode of operation of a linear collider (like NLC/JLC and CLIC) one must depress long-range transverse wakefields. In order to do this, each of the structure cells is fabricated with four holes for dipole mode damping [11]. These holes enhance surface magnetic fields $\sim 1.7$ times, pulse heating $\sim 3$ times and thus limit the available accelerating gradient to only about $100 \mathrm{MeV} / \mathrm{m}$. One of the possible solutions for relaxing limitations imposed by pulse heating is to operate in the single-bunch mode (as, for example, in [12]), where damping of long-range transverse wakefields is not required, and consequently where holes for the dampers are not necessary. Besides, the pulse width can be much shorter, which in turn should increase the breakdown limit. Note that input and output couplers also will give some enhancement as well. In the structure described here this additional limitation does not exist because the input cell with $\mathrm{TM}_{020}$ mode is employed. Even in this case the iris edges should be properly rounded in order to avoid surface magnetic field enhancement.

\section{REFERENCES}

[1] O.A. Nezhevenko, et al, EPAC2000, Vienna 2000, p.2087.

[2] J.W. Wang and G.A. Loew, SLAC-PUB-7684, October 1997.

[3] O.A. Nezhevenko, et al, PAC95, Dallas 1995, p.1076.

[4] O.A.Nezhevenko and V.P. Yakovlev, PAC99, New York 1999, p.3492.

[5] C. Adolfsen, et al, SLAC-PUB-8573, August 2000.

[6] R.J. Loewen, et al, SLAC-PUB-8399, March 2000.

[7] W. Wuensch, et al, EPAC2000, Vienna 2000, p.271.

[8] D.G. Myakishev and V.P. Yakovlev, PAC95, Dallas, 1995, p.2348.

[9] O.A. Nezhevenko, PAC97, Vancouver 1997, p.3013

[10] D.P. Pritzkau and R.H. Sieman, SLAC-PUB-8554, August 2000.

[11] I. Wilson, et al, CERN/PS 2000-057 (RF), August, 2000

[12] V.E. Balakin et al, $12^{\text {th }}$ Int. Conf. On High Energy Accelerators, Fermilab, 1983, p. 119. 